\title{
СТРУКТУРА БАЗЫ ДАННЫХ ДЛЯ ОБЪЕКТОВ ЭКОЛОГИЧЕСКОГО МОНИТОРИНГА - ПОЛИГОНОВ ТВЕРДЫХ БЫТОВЫХ ОТХОДОВ
}

\author{
Н. А. Корабельников, Ю. М. Зинюков \\ Воронежский государственный университет
}

Поступила в редакцию 8 мая 2019 г.

\begin{abstract}
Аннотация: в статье приводится характеристика компьютерной базы данных информации, созданной и реализованной в процессе ведения мониторинга различных компонентов природной среды территории размещения полигонов твердых бытовых отходов (мониторинга подземных и поверхностных вод, почв, атмосферного воздуха, растительности и шумового загрязнения). Реализованная база данных представляет собой совокупности реляционных (двумерных) таблии, объединенных в иерархическую структуру, в которой выделяются три информационно-логических уровня. Функционирование базы данных позволяет оптимизировать все этапь ведения мониторинга.
\end{abstract}

Ключевые слова: база данных; полигон твердых бытовых (коммунальных) отходов; мониторинг природной среды; информационный объект; ключевое поле; таблица данных.

\section{STRUCTURE DATABASES FOR OBJECTS ENVIRONMENTAL MONITORING - LANDFILLS}

\begin{abstract}
: this article provides a description of a computer database of information created and realized in the process of monitoring the various components of the natural environment area accommodation landfills (the monitor-ring groundwater and surface water, soil, air, vegetation and noise pollution). Realized database is a set of relational (two-dimensional) table, united in a hierarchical structure in which there are three information-logical levels. The functioning of the database makes it possible to optimize all stages of monitoring.
\end{abstract}

Key word: database; solid waste landfill; environmental monitoring; information object; key field; data table.

\section{Введение}

Федеральный закон «Об охране окружающей среды» обязывает субъектов хозяйственной деятельности проводить производственный экологический контроль, который на предприятиях с длительным циклом эксплуатации, подобных полигонам по обезвреживанию и захоронению промышленных и бытовых отходов (полигоны твердых бытовых (коммунальных) отходов (ТБО (ТКО)), проводится в форме мониторинга окружающей природной среды.

Такого рода техногенные объекты чаще всего рассматриваются как эколого-геологические системы, претерпевшие определенного рода техногенные изменения [1]. Основные компоненты геологической среды - верхней части литосферы, такие как почвы, грунты зоны аэрации, подземные воды, а также приземный слой атмосферы, поверхностные воды, биотические компоненты, физико-магнитные поля определяют структуру природно-техногенных систем такого рода.
Организация и ведение мониторинга территорий ТБО - это система наблюдений, включающая в себя формирование многоцелевой информационно-справочной системы или автоматизированной информационной системы (АИС), предназначенной для обеспечения широкого спектра задач, в том числе обеспечение экологической безопасности объектов природной среды. Компьютерная база данных (БД) является основой автоматизированных информационных систем, позволяющая использовать результаты мониторинга наиболее эффективно.

Разработанная авторами структура базы данных детального уровня мониторинга базируется на многолетнем опыте работ на группе полигонов ТБО. Практическое воплощение данная база данных получила при ведении мониторинга на таких объектах как полигон ТБО ООО «Каскад» г. Воронеж, полигон ТБО «Экосфера» и полигон ТБО муниципального предприятия г. Воронежа по обращению с отходами, а также находит свое применение на некоторых анало- 
гичных объектах [2, 3]. Данная база данных реализована в среде СУБД MS Access [4].

В соответствие с действующими нормативами [5], на территории размещения полигонов ТБО должен производиться контроль состояния подземных и поверхностных вод, почв и растений, атмосферного воздуха, шумового загрязнения, уровня радиоактивности. В конечном итоге, структура базы данных определяется совокупностью объектов мониторинга и характером наблюдаемых пунктов контроля.

Таким образом, характеризуемая база данных рассматривается как совокупность реляционных таблиц, объединенных в иерархическую структуру. Таблицы двумерные, представленные в трех информационнологических уровнях [6]. На рис.1 можно наблюдать логическую организацию данных.

Информационно-логический уровень № 1 включает в себя информацию об объектах: местоположение, административная принадлежность и т.п. Такого рода данные сведены в таблице «Объекты мониторинга».

Информационно-логический уровень № 2 пред ставляет собой таблицы, содержащие информацию о пунктах ведения мониторинга: наблюдательных скважинах, участках отбора проб поверхностных вод, почв, растений, атмосферного воздуха, замера уровня шума. В таблицах данного уровня приводится характеристика пунктов наблюдения и информация об их местоположении.

Информационно-логический уровень №3 содержит информацию об отобранных пробах и результатах их аналитических определений.

Иерархическая структура позволяет масштабировать БД путем добавления объектов мониторинга до локального и регионального уровня, что связывается с еe соответствием структурно-организационному принципу системы мониторинга как многоуровневой иерархической структуре. На второй информационнологический уровень можно добавлять таблицы, что позволяет расширять набор объектов в системе «полигон ТБО». Добавление таблиц на третий информационно-логический уровень позволяет расширять список параметров природной среды.

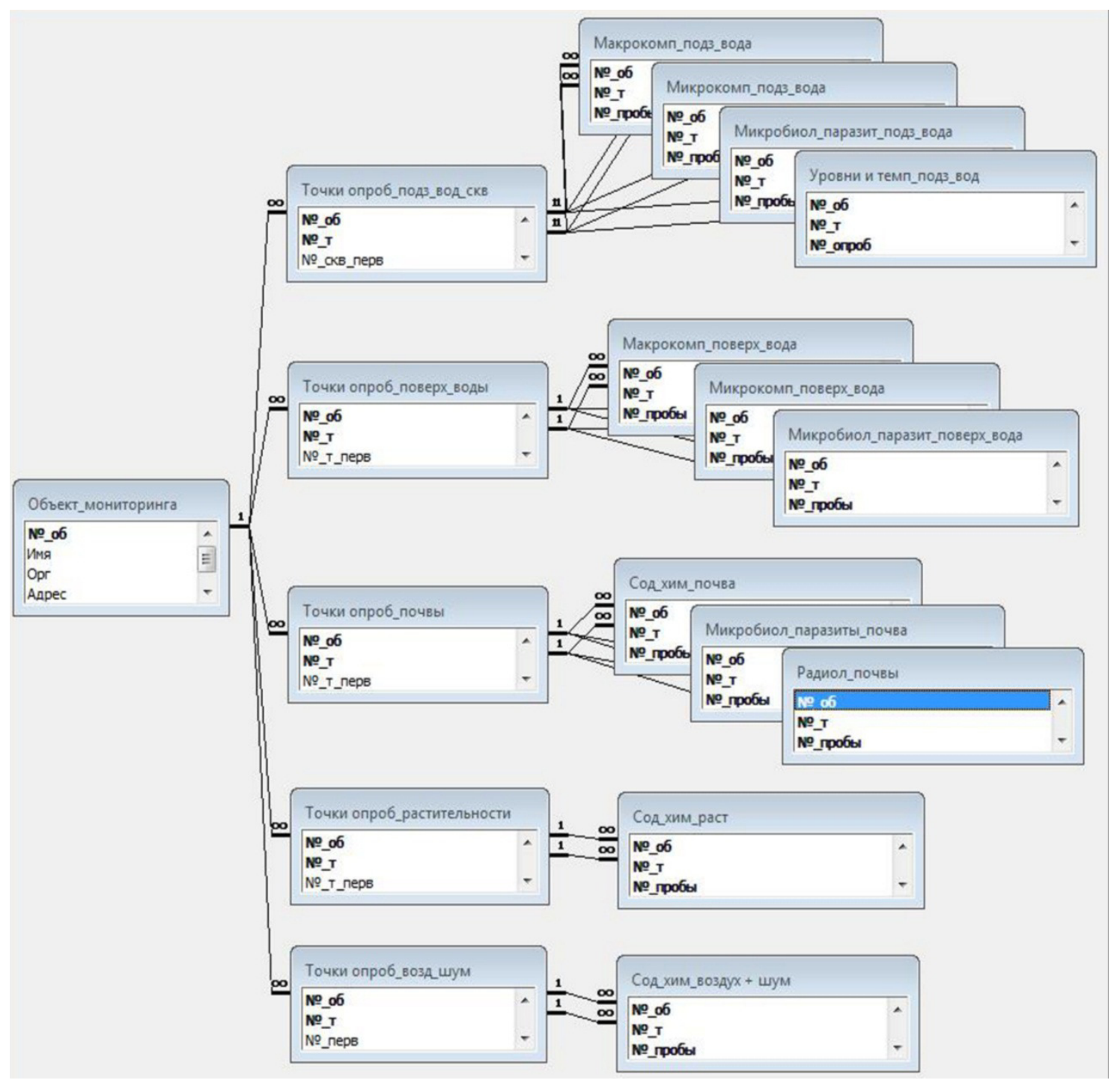

Puc. 1. Структура базы данных экологического мониторинга полигонов ТБО. 
Связи между таблицами и их характер, представляемый как «один ко многим»- определяются структурой данных проводимых исследований: в одном объекте мониторинга присутствует несколько таблиц, характеризующих точки опробования наблюдаемых сред, и таблицы, содержащие данные аналитических определений наблюдаемых компонентов.

Информаџионно-логический уровень № 1 характеризует контролируемые объекты (рис.1).

Структура информационного объекта «Объекты мониторинга» представлена в табл. 1 .

«Номер объекта» является определяющим полем (ключевым), по которому однозначно определяется каждый из объектов мониторинга. Через данное поле таблица связывается с таблицами следующего информационно-логического уровня.

Поле «Карта» - это так называемый OLE-объект. Данное поле содержит ссылку на растровую форму картографической модели, которая хранится в отдельном каталоге.

Что же касается остальных описательных полей таблицы «Объекты мониторинга», то их смысловое значение понятно по контексту.

Структура информационного объекта «Объекты мониторинга»

Таблица 1 Поле $\quad$ Признак $\quad$ Формат поля

\begin{tabular}{|c|c|c|c|c|c|}
\hline \multicolumn{2}{|c|}{ Поле } & \multirow{2}{*}{ Признак } & \multicolumn{3}{|c|}{ Формат поля } \\
& Ключа & Описание & Тип & Формат & Точность \\
\hline № объекта & Номер объекта & $*$ & Числовой & Байт & \\
\hline Имя & Наименование объекта & & Текстовый & 15 & \\
\hline Орг & Организация владелец & & Текстовый & 50 & \\
\hline Адрес & Административный адрес & & Текстовый & 150 & \\
\hline Карта & Обзорная карта & & ОLЕ объект & & \\
\hline
\end{tabular}

Информационно-логический уровень № 2 базы данных представлен пятью реляционными таблицами. Все таблицы содержат информацию об отдельных видах пунктов наблюдений. Первая реляционная таблица - «Точки опробования подземных вод - скважины» - информация о наблюдательных скважинах; вторая реляционная таблица - «Точки опробования поверхностных вод» - информация о пунктах отбора поверхностных вод; третья реляционная таблица «Точки опробования почв» - информация о пунктах отбора почвогрунтов; четвертая реляционная таблица
- «Точки опробования растительности» - информация о пунктах отбора растительности; пятая реляционная таблица - «Точки опробования воздуха и шум» - информация о пунктах замера содержания веществ в воздухе и пунктах замера уровня шума.

Таблицы по структурируемой информации характеризуется тождественностью и отличаются лишь набором конкретных характеристик. В табл. 2 приведена информационная структура объекта «Точки опробования подземных вод - скважины».

Таблица 2

Информационная структура объекта «Точки опробования подземных вод - скважиныл»

\begin{tabular}{|c|c|c|c|c|c|}
\hline \multicolumn{2}{|r|}{ Поле } & \multirow{2}{*}{$\begin{array}{c}\text { Признак } \\
\text { ключа }\end{array}$} & \multicolumn{3}{|c|}{ Формат поля } \\
\hline Имя поля & Описание & & Тип & Формат & Точность \\
\hline №_об & Номер объекта & $*$ & Числовой & Байт & \\
\hline №_T & Номер точки наблюдения (скважины) & $*$ & Числовой & Целое & \\
\hline №_cкв_перв & Номер точки наблюдения (скважины) & & Текстовый & 20 & \\
\hline Мест & Словесная привязка скважины & & Текстовый & 100 & \\
\hline X_ДГ & Коорд. Х (долгота)- десятичные градусы & & Числовой & Действит. & 11,8 \\
\hline Y_ДГ & Коорд. Y (широта) - десятичные градусы & & Числовой & Действит. & 11,8 \\
\hline X_M & Коорд. Х (долгота)- местная система, м & & Числовой & Действит. & 9,2 \\
\hline Y_M & Коорд. Y (широта) - местная система, м & & Числовой & Действит. & 9.2 \\
\hline $\mathrm{AO}$ & Абсолютная отметка устья скважины, м & & Числовой & Действит. & 6,2 \\
\hline Оголов & Высота оголовка скважины, м & & Числовой & Действит. & 6,2 \\
\hline Глуб & Глубина скважины & & Числовой & Действит. & 6,2 \\
\hline Низ_ф & Глубина низа фильтра & & Числовой & Действит. & 6,2 \\
\hline Bepx_ф & Глубина верха фильтра & & Числовой & Действит. & 6,2 \\
\hline УПВ & Глубина уровня подземных вод & & Числовой & Действит. & 6,2 \\
\hline АО_УПВ & Абс. отм. уровня подземных вод & & Числовой & Действит. & 6,2 \\
\hline $\mathrm{B} \Gamma$ & Наименование водоносного горизонта & & Текстовый & 100 & \\
\hline Инд & Геологический индекс водоносного горизонта & & Текстовый & 20 & \\
\hline
\end{tabular}


Информационно-логический уровень № 2 позволяет в таблицах однозначно идентифицировать информацию по составному ключу - «Номер объекта» и «Номер точки опробования» и связывать информацию с таблицами следующего уровня.

Структура таблиц включает следующие поля, которые характеризуют пункты опробования: номер пункта наблюдения по первоисточнику, вербальная привязка скважины, координата X (в градусах), координата Y (в градусах), координата X (в местной системе), координата Y (в местной системе).

База данных, за счет наличия в структуре данных географических координат, рассматривается как основа для представления мониторинга в виде геоинформационной системы (ГИС).

Таблица «Точки опробования подземных вод», помимо общих точек полей, включает и специальные, в которых присутствуют следующие характеристики: абсолютная отметка устья скважины, глубина скважины, высота оголовка скважины, глубина нижней части фильтра, глубина верхней части фильтра, глубина уровня подземных вод, абсолютная отметка уровня подземных вод, геологический индекс, наименование водоносного горизонта.

Поля, характеризующие объекты в таблице «Точки опробования поверхностных вод», содержат следующую информацию: абсолютная отметка уреза воды, тип водоема (водотока), название водоема (водотока), краткая характеристика, характеристика растительности в водоеме (водотоке), скорость течения.

В таблице «Точки опробования почв» содержится информация: глубина опробования, тип почвы, ан- тропогенные изменения, геоморфологическая характеристика.

Таблица «Точки опробования растительности» содержит следующую специфическую информацию: вид растительности, характеристика окружающего ландшафта.

Информационно-логический уровень №3 представлен группами таблиц, содержащих информацию аналитических и полевых исследований о физикохимическом состоянии отдельных компонентов природных сред в точках опробования. В представленных таблицах данные идентифицируются по ключевым полям: «Номер объекта», «Номер точки опробования» и «Номер пробы».

Состояние важнейшего элемента геологической среды - подземных вод отражается в виде отдельных реляционных таблиц: макрокомпоненты, микрокомпоненты, показатели микробиологического состава, уровни и температура подземных вод. Подземные воды характеризуются таблицами, включающими данные о микрокомпонентах, макрокомпонентах и микробиологическом составе вод.

В табл. 3 приводится информационная структура объекта «Макрокомпонентный состав подземных вод».

Каждое поле, содержащее количественные показатели отдельного компонента (для всех таблиц, содержащих результаты аналитических исследований), сопровождается логическим полем, которое имеет значение «Истина», если показатель определен точно, и «Ложь», если показатель имеет значение ниже границы чувствительности аналитических определений.

Таблица 3

Информационная структура объекта «Макрокомпонентный состав подземных вод»

\begin{tabular}{|c|c|c|c|c|c|}
\hline \multicolumn{2}{|r|}{ Поле } & \multirow{2}{*}{ Признак ключа } & \multicolumn{3}{|c|}{ Формат поля } \\
\hline Имя поля & Описание & & Тип & Формат & Точность \\
\hline 1 & 2 & 3 & 4 & 5 & 6 \\
\hline №_об & Номер объекта & $*$ & Числовой & Байт & \\
\hline №_T & Номер точки наблюдения & $*$ & Числовой & Целое & \\
\hline №_пробы & Номер пробы & $*$ & Числовой & Целое & \\
\hline №_пр_перв & $\begin{array}{c}\text { Номер пробы } \\
\text { по первоисточнику }\end{array}$ & & Текстовый & 50 & \\
\hline Дата & Дата опробования & & Дата/время & & \\
\hline Запах_балл & Запах в баллах & & Числовой & Байт & \\
\hline Запах_текст & Запах - описание & & Текстовый & 50 & \\
\hline Цвет_балл & Цветность в баллах & & Числовой & Действит. & 5,2 \\
\hline Цвет_текст & Цветность - описание & & Текстовый & 50 & \\
\hline Прозр_балл & Прозрачность в баллах & & Числовой & Действит. & 5,2 \\
\hline Прозр_текст & Прозрачность-описание & & Текстовый & 50 & \\
\hline Водор пок & Водородный показатель & & Числовой & Действит. & 5,2 \\
\hline Водор_пок_И & Точно или меньше & & Логический & & \\
\hline Сух_ост & Сухой остаток & & Числовой & Действит. & 8,3 \\
\hline Сух_ост_И & Точно или меньше & & Логический & & \\
\hline CO3- & Карбонаты & & Числовой & Действит. & 8,3 \\
\hline СО3-_И & Точно или меньше & & Логический & & \\
\hline HCO3- & Гидрокарбонаты & & Числовой & Действит. & 8,3 \\
\hline НСО3-_И & Точно или меньше & & Логический & & \\
\hline $\mathrm{Cl}-$ & Хлориды & & Числовой & Действит. & 8,3 \\
\hline
\end{tabular}


Продолжение табл. 3

\begin{tabular}{|c|c|c|c|c|c|}
\hline 1 & 2 & 3 & 4 & 5 & 6 \\
\hline Cl-_И & Точно или меньше & & Логический & & \\
\hline SO4-- & Сульфаты & & Числовой & Действит. & 8,3 \\
\hline SO4--_И & Точно или меньше & & Логический & & \\
\hline NO2- & Нитриты & & Числовой & Действит. & 8,3 \\
\hline NO2-_И & Точно или меньше & & Логический & & \\
\hline NO3- & Нитраты & & Числовой & Действит. & 8,3 \\
\hline NO3-_И & Точно или меньше & & Логический & & \\
\hline Общ_жест & Общая жесткость & & Числовой & Действит. & 8,3 \\
\hline Общ_жест_И & Точно или меньше & & Логический & & \\
\hline Карб_жест & Карбонатная жесткость & & Числовой & Действит. & 8,3 \\
\hline Карб_жест_И & Точно или меньше & & Логический & & \\
\hline Жест_некарб & Жесткость некарбонатная & & Числовой & Действит. & 8,3 \\
\hline Жест_некарб_И & Точно или меньше & & Логический & & \\
\hline $\mathrm{Ca}++$ & Кальций & & Числовой & Действит. & 8,3 \\
\hline $\mathrm{Ca}++$ И & Точно или меньше & & Логический & & \\
\hline $\mathrm{Mg}++$ & Магний & & Числовой & Действит. & 8,3 \\
\hline $\mathrm{Mg}++\_И$ & Точно или меньше & & Логический & & \\
\hline $\mathrm{Fe}$ & Железо общее & & Числовой & Действит. & 8,3 \\
\hline $\mathrm{Fe} \_$И & Точно или меньше & & Логический & & \\
\hline NH4+ & Аммоний & & Числовой & Действит. & 8,3 \\
\hline NH4+_И & Точно или меньше & & Логический & & \\
\hline $\mathrm{Na}+$ & Натрий & & Числовой & Действит. & 8,3 \\
\hline $\mathrm{Na}+$ И & Точно или меньше & & Логический & & \\
\hline Окис_перм & Окисляемость перманганатная & & Числовой & Действит. & 8,3 \\
\hline Окис_перм_И & Точно или меньше & & Логический & & \\
\hline $\mathrm{H}_{2} \mathrm{SiO}_{3}$ & Кремнекислота & & Числовой & Действит. & 8,3 \\
\hline $\mathrm{H}_{2} \mathrm{SiO}_{3 \_}$И & Точно или меньше & & Логический & & \\
\hline Минерализация & & & Числовой & Действит. & 8,3 \\
\hline Минерализация_И & Точно или меньше & & Логический & & \\
\hline$(\mathrm{PO} 3) \mathrm{n}$ & Полифосфаты & & Числовой & Действит. & 8,3 \\
\hline (PO3)n_И & Точно или меньше & & Логический & & \\
\hline F- & Фториды & & Числовой & Действит. & 8,3 \\
\hline F-_И & Точно или меньше & & Логический & & \\
\hline $\mathrm{Fe} 2$ & Железо двухвалентное & & Числовой & Действит. & 8,3 \\
\hline Fe2_И & Точно или меньше & & Логический & & \\
\hline $\mathrm{Fe} 3$ & Железо трехвалентное & & Числовой & Действит. & 8,3 \\
\hline Fe3_И & Точно или меньше & & Логический & & \\
\hline
\end{tabular}

Состояние подземных и поверхностных вод имеют идентичное описание в реляционных таблицах. По составу макрокомпонентов воды характеризуются показателями физических свойств (цвет, мутность, прозрачность, запах, вкус) и показателями, определяющими химический тип воды $\left(\mathrm{HCO}_{3}{ }^{-}, \mathrm{SO}_{4}{ }^{2-}, \mathrm{Cl}^{-}, \mathrm{Na}^{+}\right.$, $\left.\mathrm{K}^{+}, \mathrm{Ca}^{2+}, \mathrm{Mg}^{2+}, \mathrm{NO}_{3}^{-}\right)$. Дополнительно приводятся такие показатели как температура воды, $\mathrm{pH}$, окисляемость, жесткость, $\mathrm{CO}_{2}, \mathrm{CO}_{3}{ }^{2-}, \mathrm{NH}_{4}^{+}, \mathrm{NO}_{2}^{-}, \mathrm{Fe}, \mathrm{SiO}_{2}$, сухой остаток. По составу микроэлементов воды характеризуются содержанием в воде следующих компонентов: Mn, Ti, V, Cr, Zr, Nb, Y, Ba, Sr, Ga, Ni, Co, $\mathrm{Mo}, \mathrm{Cu}, \mathrm{Rb}, \mathrm{Ag}, \mathrm{Zn}, \mathrm{Cd}, \mathrm{P}, \mathrm{Be}, \mathrm{Sc}, \mathrm{Yb}, \mathrm{Sb}, \mathrm{Sn}, \mathrm{B}, \mathrm{Br}, \mathrm{J}$, $\mathrm{U}, \mathrm{Ra}, \mathrm{He}, \mathrm{H}^{3+}$.

На полигонах ТБО особое внимание уделяют контролю микробиологических показателей подземных и поверхностных вод, таким как общие колиформные бактерии, термотолерантные колиформные бактерии, возбудители кишечных инфекций, колифаги, яйца гельминтов.
Для подземных вод информация дополняется группой данных, вынесенных в отдельную таблицу. Это уровни и температура подземных вод. Таблица содержит поля с информацией об уровне воды в скважине, температуре воды и глубине скважины.

Для характеристики приземного атмосферного воздуха используются такие показатели как аммиак, метан, сероводород, бензол, $\mathrm{CO}, \mathrm{CO}_{2}$, хлорбензол, трихлорметан, тетрахлорметан, $\mathrm{NO}, \mathrm{NO}_{2}$. В данной таблице также отражен показатель уровня шума.

Состояние почв характеризуется тремя группами показателей: содержание химических веществ в почве, микробиология почв и радиационный фон. Микробиологические показатели включают следующие характеристики: индекс БГПК, индекс энтерококков, патогенные бактерии, яйца гельминтов. Химический состав почв характеризуется следующими параметрами: водородный показатель, влажность, органические вещества, нефтепродукты, ПАВ, $\mathrm{Cl}^{-}, \mathrm{HCO}^{3-}, \mathrm{NO}^{2-}$, $\mathrm{NO}^{3-}, \mathrm{NH}^{4+}, \mathrm{Ca}^{2+}, \mathrm{Mg}^{2+}, \mathrm{Fe}, \mathrm{Zn}, \mathrm{Cd}, \mathrm{Hg}, \mathrm{Pb}, \mathrm{Cu}, \mathrm{Mn}, \mathrm{Ni}$, 


\section{$\mathrm{Cr}, \mathrm{Co}$, бен(з)апирен.}

В отдельную таблицу вынесены результаты радиационного мониторинга почвенного покрова, выраженного в анализе содержания радионуклидов в почве, которые отражают содержание следующих элементов: Cs-137; K-40; Th-232; Ra-226.

Для контроля состояния растительности определены следующие компоненты: $\mathrm{Zn}, \mathrm{Cd}, \mathrm{Hg}, \mathrm{Pb}, \mathrm{Cu}, \mathrm{Mn}$, $\mathrm{Ni}, \mathrm{Cr}$.

Оценивая полноту информации, заложенной в реализованную БД, по степени разнообразия информации:

$$
B=1-n_{u} / n_{\text {onm }},
$$

где $B$ - разнообразие информации; $n_{u}-$ набор свойств эколого-геологической системы; $n_{\text {опm }}-$ набор свойств, необходимый и достаточный для решения задачи, который мы принимаем за набор обозначенный в «Инструкции ...» [5], то ее можно считать полной $(\mathrm{B}=0)$.

Оценивая количество информации, заложенной в отдельные таблицы третьего инфологического уровня БД, величиной избыточности [7]:

$$
A_{R}=1-H / H_{\text {onm }},
$$

где $A_{R}$ - величина избыточности; $H$ - количество информации; $H_{\text {onm }}$ - количество информации, отвечающее оптимуму (в нашем случае опять же требования «Инструкции ...» [5]), то количество информации либо оптимально $\left(A_{R}=0\right)$, либо избыточно $\left(A_{R}<0\right)$.
Сформированная база данных имеет удобный интерфейс ввода информации, реализованный в виде вложенных экранных форм (рис. 2).

Ввод данных производится последовательно, в соответствии с приведенной структурой данных: от объектов мониторинга до результатов анализов отдельных проб.

БД имеет три уровня доступа: администратор, пользователь, гость.

Гость может формировать SQL-запросы и делать выборки из базы данных.

Пользователь дополнительно имеет возможность заполнять и редактировать данные.

Администратор имеет все права доступа к возможностям системы: менять пароли доступа, проводить тестирование, заполнять и редактировать словари данных, вносить изменения в структуру данных (добавлять или удалять поля в таблицах, менять размерность полей и др.).

Пользователь с правами доступа «Администратор» обладает возможностью формировать разнообразные выборки данных. Это осуществляется с помощью мастера SQL-запросов. Для остальных пользователей созданы стандартные формы запросов. Соответственно, база данных позволяет экспортировать выбранные данные в общеупотребимые форматы (.doc, .xls и др.) и иллюстрировать их в виде различных диаграмм и графиков.

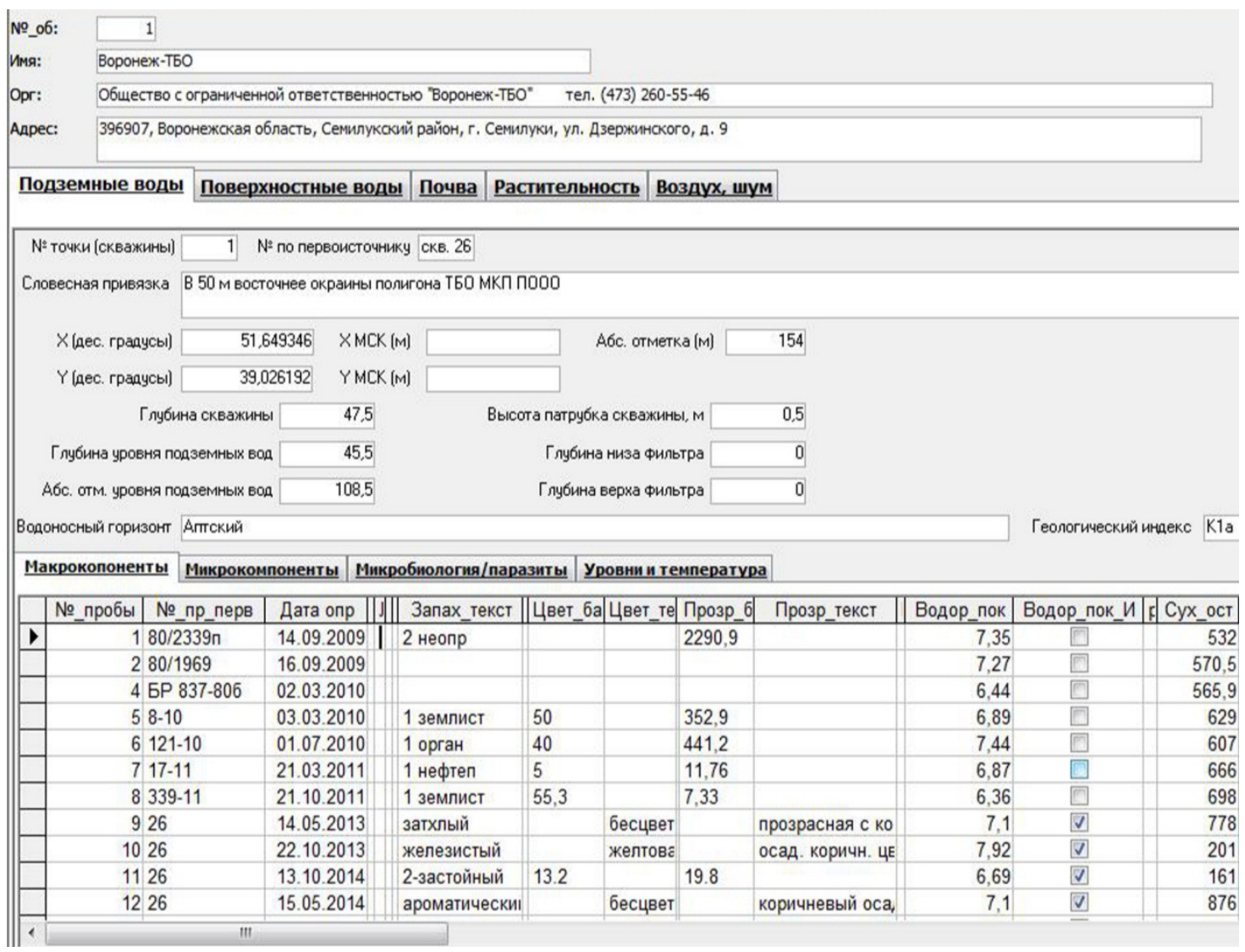

Puc. 2. Экранная форма ввода информации в таблицу «Макрокомпонентный состав подземных вод». 
Адаптация описанного информационного блока в организации мониторинговых работ - новый шаг в повышении эффективности научных форм методических исследований в районах интенсивного техногенеза, обусловленного эксплуатацией таких многокомпонентных объектов влияния на природную среду как полигоны ТБО (ТКО). Реализованная структура базы данных может служить эффективной основой для формирования баз данных экологического мониторинга.

\section{ЛИТЕРАТУРА}

1. Королёв, В. А. Мониторинг геологических, литотехнических и эколого-геологических систем / В. А. Королев; Под. ред. В.Т. Трофимова. - М.: КДУ, 2007. - 416 с.

2. Зинюков, Ю. М. Теоретико-методологические основы организации мониторинга природно-технических экосистем на основе их структурно-иерархических моделей / Ю. М.

ФГБОУ ВО «Воронежский государственный университет»

Корабельников Николай Анатольевич, преподаватель кафедры гидрогеологии, инженерной геологии и геоэкологии E-mail:akma-u@mail.ru Тел: +7 (473)2208980

Зинюков Юрий Михайлович, кандидат технических наук, дочент кафедры гидрогеологии, инженерной геологии и геоэкологии

E-mail: zinykov209@mail.ru

Тел.: + 7 (473)220 8980
Зинюков. - Труды научно-исследовательского института геологии Воронеж. гос. ун-та. - Вып. 28. - Воронеж: Изд-во Воронеж. ун-та, 2005. - 164 с.

3. Зинюков, Ю. М. Организация мониторинга природной среды в районе полигона ТБО «Каскад» (Воронежская область) / Ю. М. Зинюков, В. А. Валяльщиков // Вестник Воронеж. гос. ун-та. Сер. Геология. - 2014. - № 4. - С.98-103.

4. Михеева, В. Д. Microsoft Access 2003 / В. Д. Михеева, И.

А. Харитонова. - СПб.: БХВ-Петербург, 2004. - 1072 с.

5. Инструкция по проектированию, эксплуатации и рекультивации полигонов для твердых бытовых отходов. - М: Минстрой РФ, 1997.

6. Конноли, Т. Базы данных. Проектирование, реализация и сопровождение. Теория и практика. / Т. Конноли, К. Бегг. М.: Издательский дом «Вильяме», 2003. - 1440 с.

7. Бондарик, Г.К. Инженерная геология. Вопросы теории и практики. Философские и методологические основы геологии / Г. К. Бондарик, Л. А. Ярг. - М.: ИД КДУ, 2015. - 296 с.

\section{Voronezh State University}

Korabelnikov N. A., lecturer of the Hydrogeology, Engineering Geology and Geoecology Department

E-mail:akma-u@mail.ru

Tel: +7 (473)220 8980

Zinyukov Yu. M., candidate of technical Sciences, associate professor lecturer of the Hydrogeology, Engineering

Geology and Geoecology Department

E-mail: zinykov209@mail.ru

Tel: +7 (473)2208980 